\title{
Isolated AC/AC Converter with LLC Resonant Converter High Frequency Link and Four- Quadrant Switches in the Output Stage
}

\author{
Leonardo F. Pacheco, (Student Member, IEEE), Kaio C. M. Nascimento, (Student member, \\ IEEE), and Ivo Barbi, (Life Fellow, IEEE). \\ Federal University of Santa Catarina, Florianópolis, SC 88054-700 Brazil
}

Corresponding author: Leonardo F. Pacheco (e-mail: leofpacheco2@gmail.com).

This work was supported by Companhia Energética de Brasília (CEB), as part of R\&D Program ANEEL 001/2016.

\begin{abstract}
An AC-AC converter with high-frequency link employing LLC resonant converter operating in the vicinity of the resonance frequency is studied, in which the output stage is unique and formed by a high-frequency AC-AC converter employing four quadrant switches. The topology, its operation and the modulation strategy are presented. The high-frequency stage switches located on the primary side of the transformer operate with soft switching of the ZVS type, while the four quadrant switches that form the output stage operate with soft switching of the ZCS type. Experimental data on a $1.5 \mathrm{~kW}$ experimental prototype that was designed, built and tested in the laboratory, with $220 V_{R M S}$ input, $220 V_{R M S}$ output and $40 \mathrm{kHz}$ switching frequency are given in the paper. The studied converter can be considered a candidate for the building block of medium voltage solid-state transformers (SST) for power distribution systems.
\end{abstract}

INDEX TERMS AC-AC converter, high-frequency link, LLC converter, soft-commutation, solid-state transformer.

\section{INTRODUCTION}

The isolated AC-AC converter with a high frequency link is the basic building block of solid-state transformers [1]-[6]. Many topologies and architectures can be found in the literature, the oldest being that proposed in [1], and [2], which operation principle can be describe using the topology shown in Fig. 1.

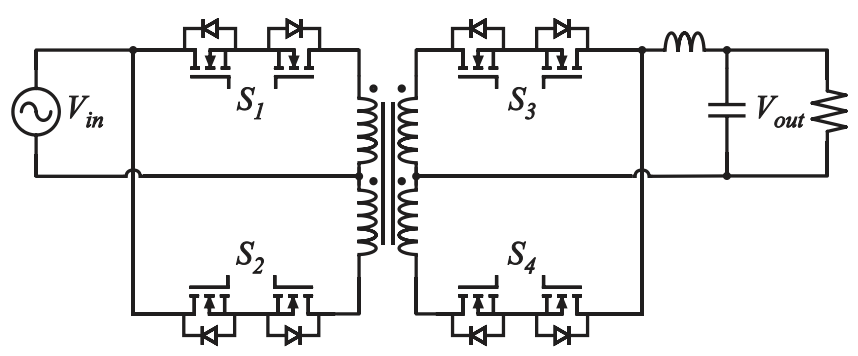

FIGURE 1. Phase-controlled AC-AC converter with high frequency link.

The AC input voltage $V_{\text {in }}$ is chopped by the four quadrant switches $S_{1}$ and $S_{2}$, generating a high frequency amplitude modulated voltage, which is applied to the high frequency transformer. A low frequency sinusoidal voltage $V_{\text {out }}$ is reconstructed at the output terminals by the four quadrant switches $S_{3}$ and $S_{4}$, modulated by phase shift and synchronized with respect to the sinusoidal input voltage. Despite its simplicity, this topology is limited in its practical use, as it presents commutation difficulties, low efficiency and subjects the semiconductors to instantaneous voltages at least equal twice the peak value of the input voltage.

The maturing of the concept, together with the evolution of semiconductors, resulted in the architecture shown in Fig. 2 , in which the $60 \mathrm{~Hz}$ input sinusoidal voltage is rectified by the folding bridge, generating a rectified $120 \mathrm{~Hz}$ sinusoidal voltage [3], [4], [7]. The second stage consists of a LLC resonant converter, operating at the resonant frequency, a condition that ensures soft commutation of the switches. In addition, at this frequency, the voltage static gain of this stage depends only on the transformer turns ratio, as the impedance displayed by the LLC converter seen from the output terminals is theoretically null. 


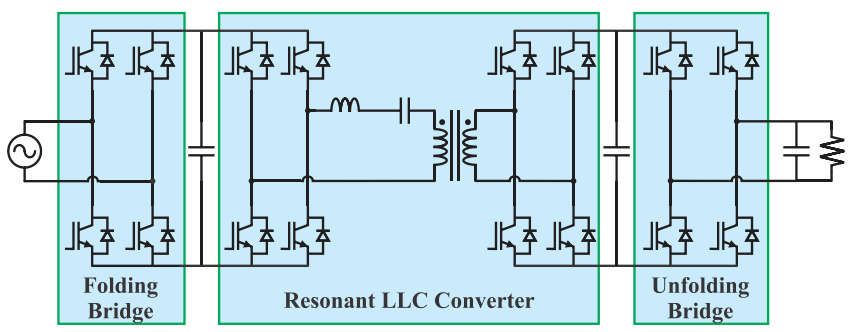

FIGURE 2. AC-AC converter using the series resonant LLC converter as high frequency link.

The last stage is an unfolding bridge, operating at a frequency of $60 \mathrm{~Hz}$, and synchronized with the input sinusoidal supply voltage, generating a sinusoidal voltage in the load, which is an image of the input sinusoidal voltage.

In order to reduce the number of semiconductors, the set formed by the output rectifier of the LLC resonant converter and the unfolding bridge, was replaced by a stage formed by four quadrant switches in [8], where a simplified description of the operation of the converter was presented, without experimental results. The studied topology, which is shown in Fig. 3, can be considered a combination of the converter shown in Fig. 1Figure 1, with that shown in Fig. 2.

In this paper, an in-depth analysis of the converter is presented, with the inclusion of experimental results obtained from an experimental prototype designed, built and tested in the laboratory, with the purpose of verifying its performance and its potential to be used as a building bloc in solid-state transformers.

\section{PROPOSED CONVERTER}

The AC-AC converter with high frequency isolation, using the LLC series resonant converter is shown in Fig. 3 [8], which is composed of two stages. The first stage, formed by the power semiconductors $S_{a, b, c, d}$, the inductor $L_{f}$, and the capacitor $C_{f}$, is an folding bridge, which converts the sinusoidal voltage of $60 \mathrm{~Hz}$ at the input into a sinusoidal voltage rectified at its output with frequency of $120 \mathrm{~Hz}\left(V_{C C}\right)$. The filter composed by $L_{f}$ and $C_{f}$ is designed to filter only high frequency voltages and currents, without interfering in the shape or value of the fundamental voltage waveform.
The second stage consists of an LLC resonant series converter operating at the resonance frequency, formed by the switches $S_{I, 2,3,4}$, the resonant inductor $L_{r}$, the resonant capacitor $C_{r}$, the high frequency isolation transformer $T_{1}$, and the output stage. The output stage of a conventional LLC resonant converter uses unidirectional switches and generates a voltage with only positive polarity. Thus, an additional stage must be employed, operating synchronously with the input voltage, to obtain the sinusoidal voltage at the load.

In the proposed converter, the unidirectional switches have been replaced by bidirectional ones, which properly controlled, allow to obtain output voltage with positive and negative polarities, not needing an additional stage for the reconstruction of the output low frequency sinusoidal voltage.

Thus, during the positive half-cycle of the alternating input voltage, the switches of the high frequency stage are controlled so that the voltage in the load is always positive. During the negative half-cycle of the input voltage, they are controlled so that the voltage is negative. As the LLC resonant series converter operates in the vicinity of the resonance frequency, its voltage static gain depends only on the transformer turns ratio and its equivalent circuit seen from the output terminals has theoretically zero series impedance. Thus, an output voltage that is an image of the input voltage is obtained, without the need for closed loop control.

The output capacitor $C_{o}$ is selected to absorb the high frequency current harmonics, and must have the lowest possible capacitance so as not to cause the circulation of unnecessary reactive power inside the converter.

\section{OPERATION PRINCIPLE}

The operation of the high-frequency stage of the converter with ideal components can be divided into four stages, two of which occur during the positive half-cycle of the input sinusoidal voltage, and two during the negative half-cycle. In the first operation stage shown in Fig. 4, while the sinusoidal input voltage is positive, $S_{1}$ and $S_{4}$ are gated together with $S_{F 1}$.

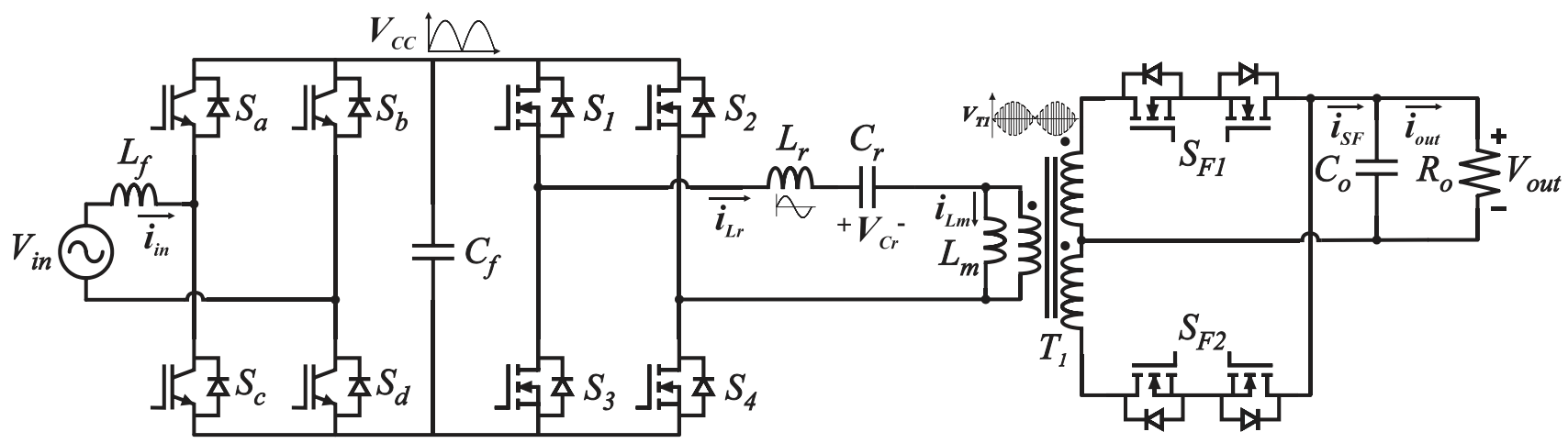

FIGURE 3. AC-AC converter with high frequency isolation using the LLC series resonant converter. 


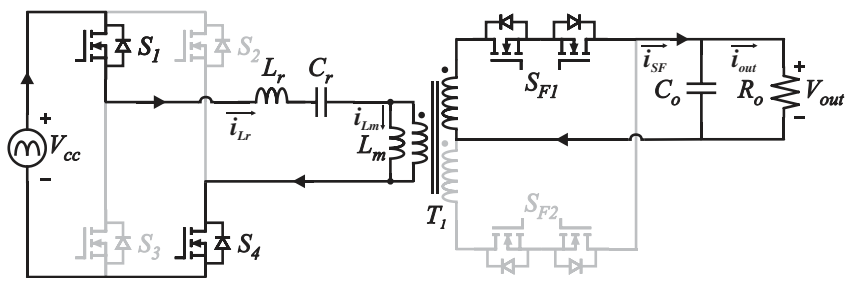

FIGURE 4. First operation stage of the converter during the positive half-cycle of the sinusoidal input voltage.

In the second operation stage, shown in Fig. 5, the input sinusoidal voltage is still positive, and $S_{2}$ and $S_{3}$ are gated with $S_{F 2}$, at the instant the resonant current reverses its polarity.

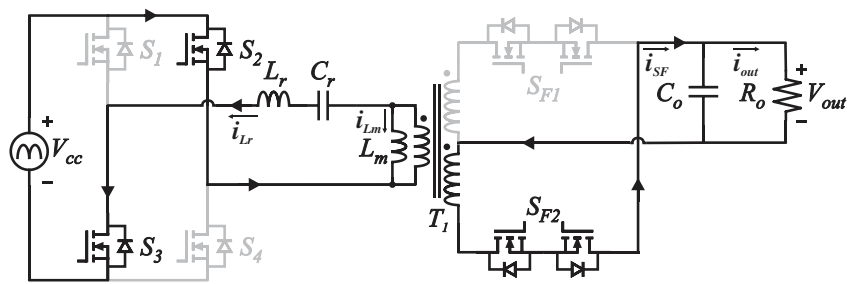

FIGURE 5. Second operation stage of the converter during the positive half-cycle of the sinusoidal input voltage.

These first two topological states are repeated at the switching frequency until the instant the input sinusoidal voltage becomes negative. The corresponding typical waveforms are shown in Fig. 6.
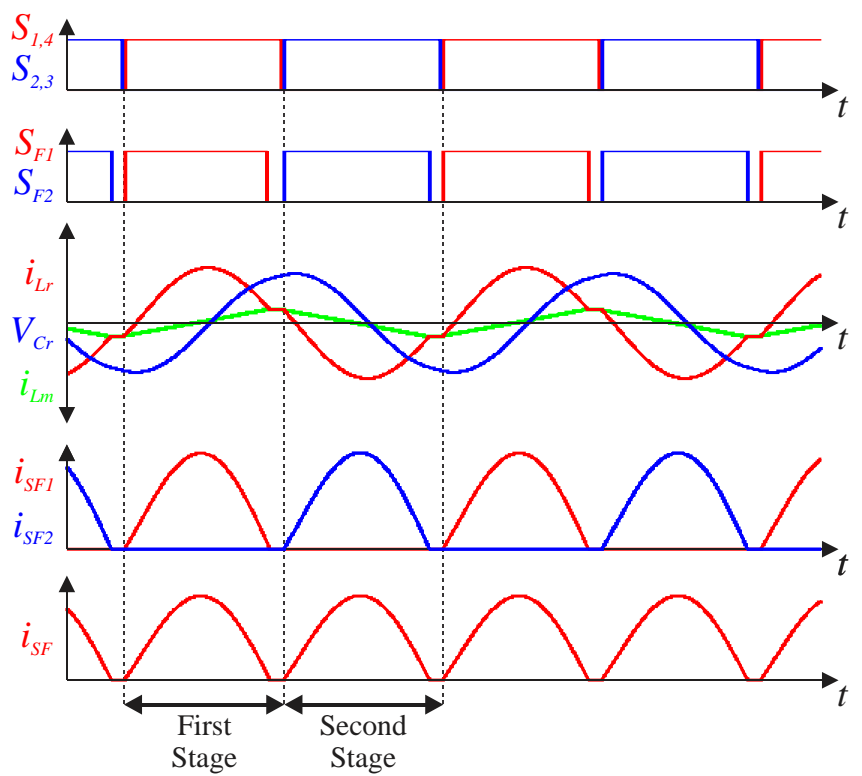

FIGURE 6. Relevant waveforms during the positive half-cycle of the sinusoidal input voltage.

The first topological state, during the negative half-cycle of the sinusoidal input voltage, is shown in Fig. 7, where switches $S_{2}$ and $S_{3}$ are gated with switch $S_{F 1}$.

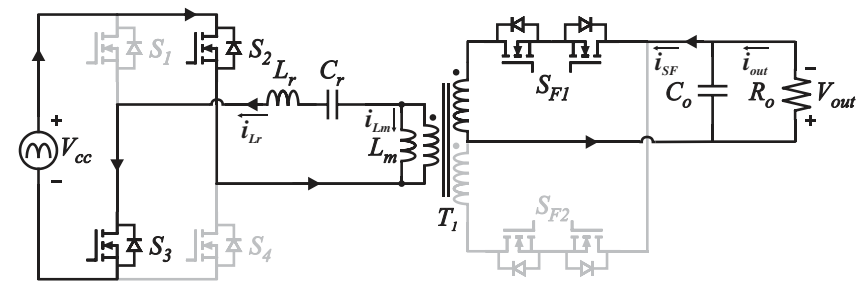

FIGURE 7. First operation stage of the converter during the negative half-cycle of the sinusoidal input voltage.

During the second topological state, shown in Fig. 8, switches $S_{1}$ and $S_{4}$ are gated together with the switch $S_{F 2}$, at the moment the current in the resonant inductor reverses its direction.

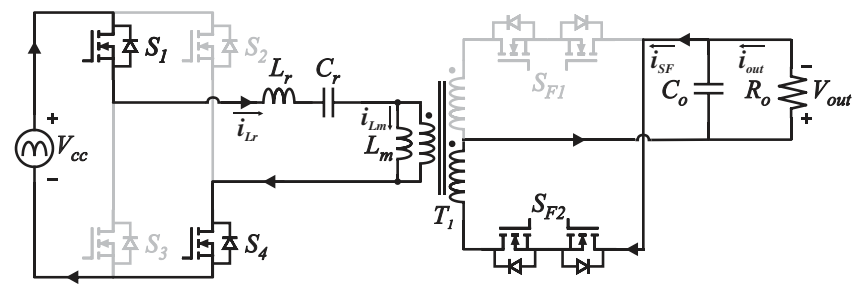

FIGURE 8. Second operation stage of the converter during the negative half-cycle of the sinusoidal input voltage.

Typical waveforms for these two operating stages are shown in Fig. 9.
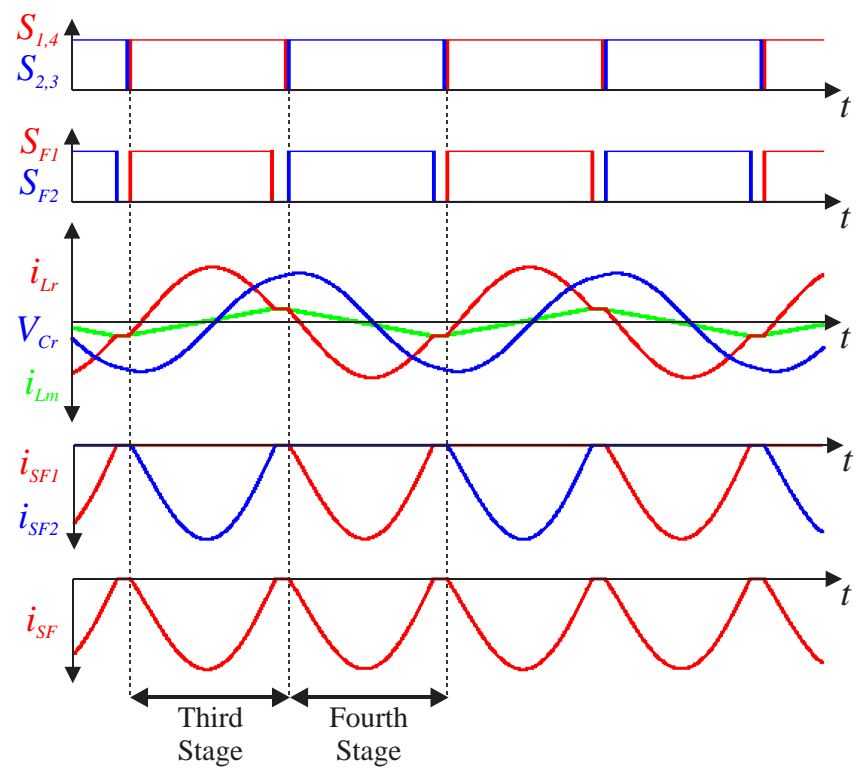

FIGURE 9. Relevant waveforms during the negative half-cycle of the sinusoidal input voltage.

The input stage voltages and currents waveforms are shown in Fig. 10. 


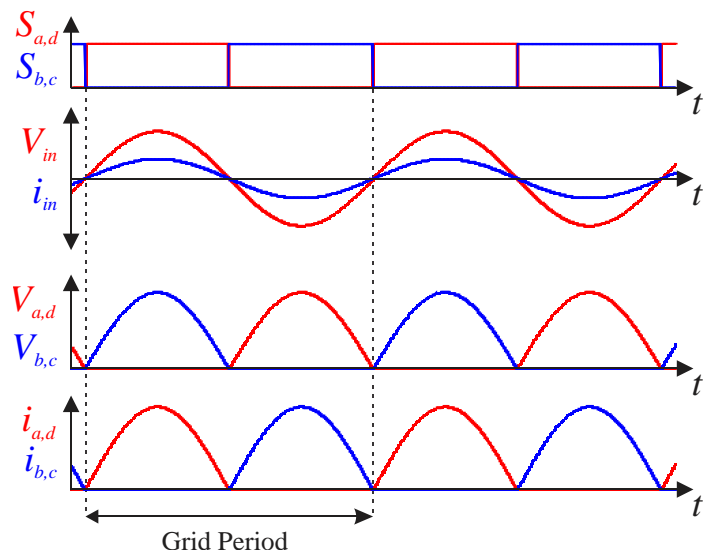

FIGURE 10. Gate signals, input voltage and current waveforms, and voltage and current waveforms in the power semiconductors of the input folding bridge.

The theoretical voltage and current waveforms in the switches $S_{1}$ and $S_{4}$ of the LLC converter are shown in Fig. 11. The waveforms on switches $S_{2}$ and $S_{3}$ are identical to those of switches $S_{1}$ and $S_{4}$.
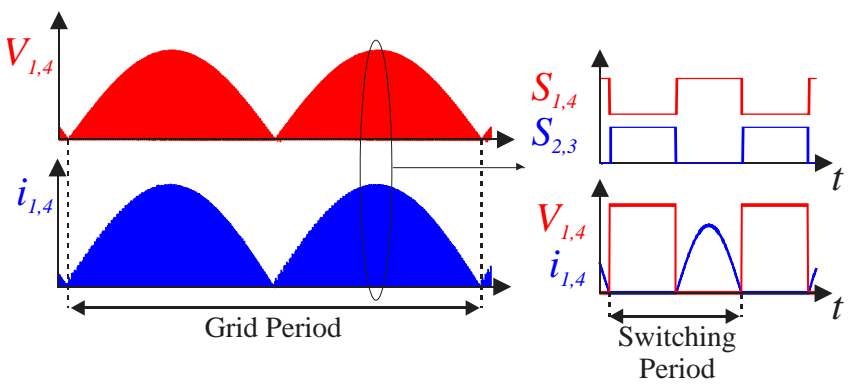

FIGURE 11. Voltage and current waveforms in the power semiconductors $S_{1}$ and $S_{4}$ of the resonant LLC stage.

The waveforms of the currents through the power semiconductors $S_{F 1}$ and $S_{F 2}$ of the converter output stage are shown in Fig. 12.

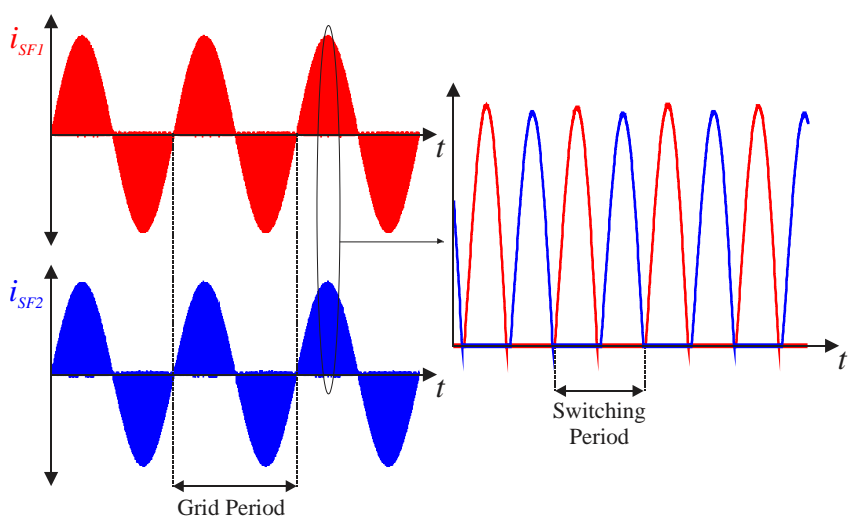

FIGURE 12. Waveforms of the currents through the power semiconductors $S_{F 1}$ and $S_{F 2}$ of the output stage.

The sinusoidal voltage and current at the output terminals of the converter are shown in Fig. 13.

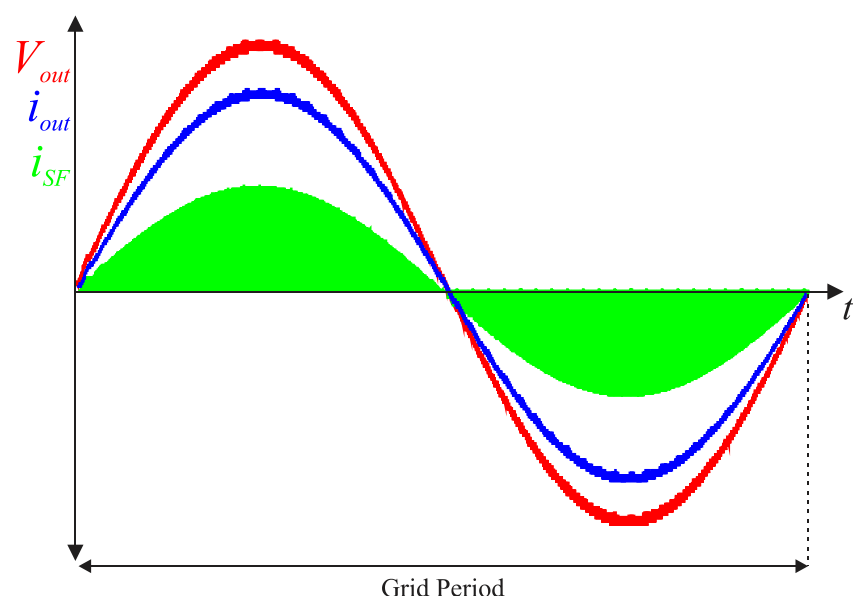

FIGURE 13. Waveforms of the sinusoidal output voltage, the output current, and the unfiltered output current.

\section{STEADY-STATE ANALYS}

\section{A. Voltage Static Gain}

The input rectifier stage operates at a much lower frequency than the switching frequency of the LLC converter. For this reason, the LLC converter can be considered to be powered by direct voltage and represented by its equivalent circuit in steady state. The voltage static gain of the LLC converter with transformer turns ratio equal to unity is given by [9].

$$
M=\frac{\mu_{o}^{2}}{\sqrt{\left[\mu_{o}^{2}(\lambda+1)-\lambda\right]^{2}+\left[\mu_{o} \cdot Q\left(\mu_{o}^{2}-1\right)\right]^{2}}}
$$

where

$$
\lambda=\frac{L_{r}}{L_{m}}, \mu_{o}=\frac{f_{s}}{f_{r}}, Q=\frac{1}{R_{a c}} \sqrt{\frac{L_{r}}{C_{r}}}, \text { and } R_{a c}=\frac{8}{\pi^{2}} R_{o} .
$$

The resonance frequency of the converter depends only on the capacitance $C_{r}$ of the resonant capacitor and the inductance $L_{r}$ of the resonant inductor, and is determined by

$$
f_{r}=\frac{1}{2 \cdot \pi \cdot \sqrt{L_{r} \cdot C_{r}}}
$$

Fig. 14 shows the voltage static gain of the LLC converter as a function of the normalized switching frequency, with transformer turns ratio equal to unity, for different quality factors [9]. 


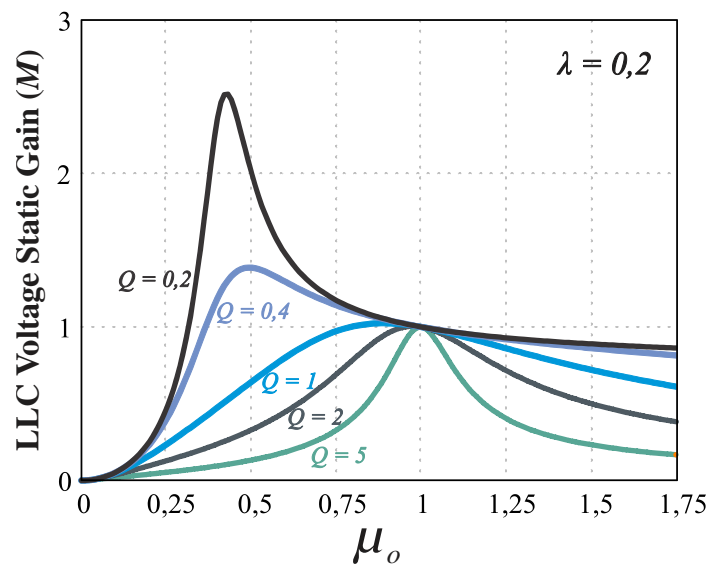

FIGURE 14. Voltage static gain of the LLC converter as a function of the normalized switching frequency for the transformer with turns ratio equal to unity, and different values of quality factor $Q$.

When the switching frequency $f_{s}$ is equal to the resonant frequency, the static gain of the ideal converter is unitary and independent of the load. Therefore, this operating frequency is selected, and the gain of the converter is determined by the transformer turns ratio.

\section{B. Power Semiconductor's Voltage and Current Stress}

For proper selection of the power semiconductors, it is necessary to calculate their average, effective and maximum current values and maximum voltage. The expressions for calculating these quantities are shown in Table I.

TABLE I

EXPRESSIONS FOR CALCULATION OF POWER SEMICONDUCTOR'S VOLTAGE AND CURRENT STRESS

\begin{tabular}{|c|c|c|c|c|}
\hline & $S_{a, b, c, d}$ & $S_{1,2,3,4}$ & & $S_{F l, F 2}$ \\
\hline \multirow{2}{*}{$\begin{array}{l}\text { Peak } \\
\text { Current }\end{array}$} & $V_{o_{-} \text {peak }}$ & $V_{o_{-} \text {peak }}$ & $\pi$ & $V_{o_{\text {_p peak }}} \pi$ \\
\hline & $R_{o}$ & $R_{o}$ & 2 & $R_{o}$ \\
\hline \multirow[t]{2}{*}{$\begin{array}{l}\text { Average } \\
\text { Current }\end{array}$} & $V_{o_{-} \text {peak }} 1$ & $V_{o_{-} \text {peak }}$ & 1 & $V_{o_{-} \text {peak }} 2$ \\
\hline & $R_{o} \pi$ & $R_{o}$ & $\bar{\pi}$ & $R_{o} \quad \overline{\pi^{2}}$ \\
\hline \multirow{2}{*}{$\begin{array}{l}\text { RMS } \\
\text { Current }\end{array}$} & $\underline{V_{o_{-} \text {peak }}} \underline{1}$ & $V_{o_{-} \text {peak }}$ & $\pi$ & $\underline{V_{o_{-} \text {peak }}} 1$ \\
\hline & $R_{o} \quad 2$ & $R_{o}$ & 2 & $R_{o} \quad 2 \sqrt{2}$ \\
\hline $\begin{array}{l}\text { Peak } \\
\text { Voltage }\end{array}$ & $V_{\text {in_peak }}$ & $V_{\text {in_peak }}$ & & $2 V_{\text {in_peak }}$ \\
\hline
\end{tabular}

With these data in hand, it is possible to select the components of the power stage that will withstand such stress and provide the correct converter operation.

\section{Transformer Turns Ratio}

As mentioned in the previous section, since the LLC converter operates in the vicinity of the resonant frequency, its voltage static gain is determined by the transformer turns ratio, defined by

$$
a=\frac{V_{\text {out }}}{V_{\text {in }}}
$$

\section{COMMUTATION QUALITATIVE ANALYSIS}

In order to achieve high efficiency and EMI reduction, soft switching of the converter switches is required. Since the first power conversion stage operates at a low frequency, its switching losses can be neglected.

\section{A. Commutation of the Power Semiconductors of the LLC Converter}

To ensure soft switching of the LLC converter switches, a dead time is added between the gate signals from the same switches leg. In addition to preventing short-circuit of the converter leg, the dead time allows the commutation capacitors of the switches to charge and discharge properly, allowing zero voltage switching of the power semiconductors (ZVS). Fig. 15 illustrates correct (a) and incorrect (b) dead-time.

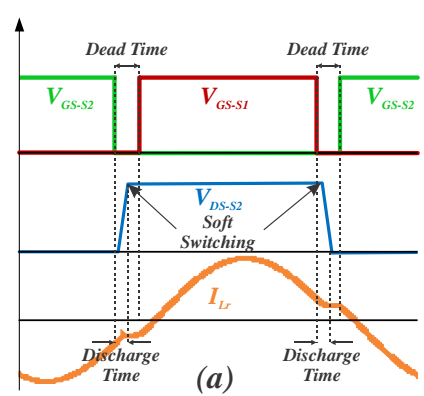

(a)

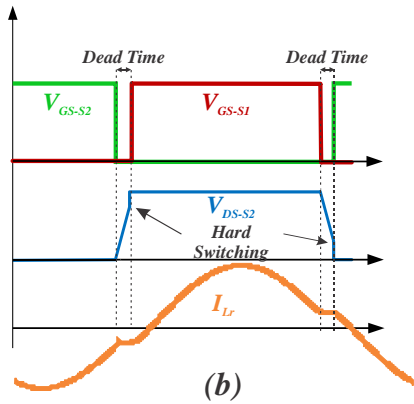

(b)
FIGURE 15. Dead time between the gate signals of the power semiconductors of a leg of the resonant LLC converter.

It is possible to use the switch's own intrinsic capacitance, if its value is appropriate. If it is too small or does not exist, a capacitor with the appropriate capacitance is added in parallel with the converter power semiconductors.

For soft switching to occur, it is important that the resonant current $\left(i_{L r}\right)$ has an appropriate value when each switch is turned OFF. An important feature of the LLC resonant converter is the fact that even when the power delivered to the load is zero, the peak value of the magnetizing current is capable of charging and discharging the commutation capacitors and ensures ZVS switching, contrary to what occurs with many other DC-DC converters.

In an LLC converter, the magnetizing current amplitude depends on the voltage applied to its transformer. Therefore, when the sinusoidal input voltage is at its peak, it will have a maximum peak magnetizing current. On the other hand, when the input voltage is close to zero, the magnetizing current smaller, making the charging and discharging of the capacitors slower.

A consequence of the inclusion of dead time is the existence of voltage spikes across terminals of the transformer, illustrated in Fig. 16, which are consequently 
reflected to the output stage switches at the instant they are turned OFF. Its value can be calculated by

$$
V_{L m}=-\left(V_{i n}+V_{L r}+V_{C r}\right)
$$

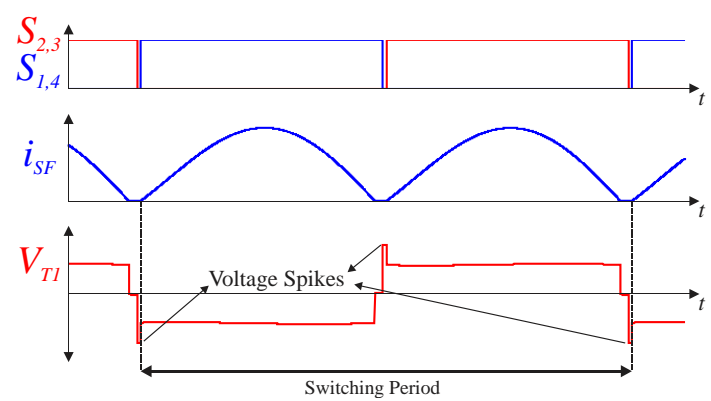

FIGURE 16. Voltage peaks at the transformer terminals due to the dead time.

\section{B. Commutation of the Output Stage Power \\ Semiconductors}

In order to have Zero Current Switching (ZCS) in the output stage switches, the switching frequency is slightly reduced in relation to the resonance frequency. Due to the nature of the LLC resonant converter, in this region of operation there are small time intervals of discontinuity in the current in the secondary stage of the transformer, as shown in Fig. 17. However, this reduction in the switching frequency, being very small, maintains the voltage static gain of the converter close to unity

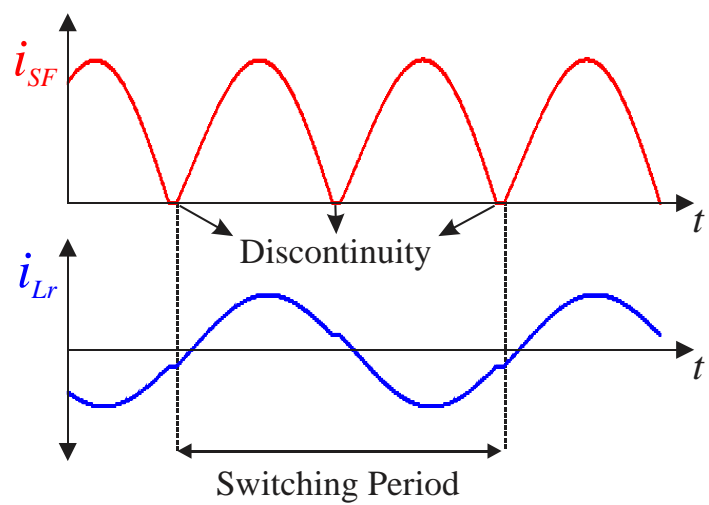

FIGURE 17. Transformer secondary current (isF) and resonant inductor current (iLr) of the LLC converter.

In the time intervals in which the current in the four quadrant switches of the output stage is zero, they must be turned OFF, so that the soft switching of the ZCS type occurs, as shown in Fig. 18.

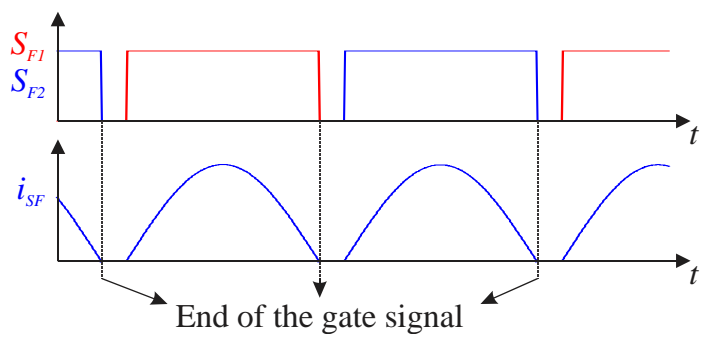

FIGURE 18. Gate signals and current in the power semiconductors of the output stage.

If the switch is turned OFF too soon, there will be hard switching as there will still be current flowing, as shown in Fig. 19 (a). If it is turned OFF too late, there will be reverse current flowing (due to the voltage and current bidirectionality of the four quadrant switch), and there will also be dissipative switching, as shown in Fig. 19 (b).

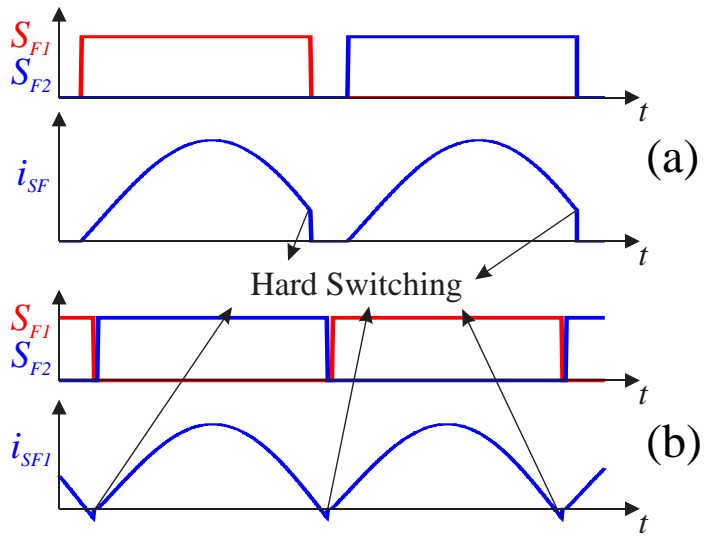

FIGURE 19. Examples of incorrect gating of the output stage switches, in which the zero-current switching does not occur.

\section{EXPERIMENTAL RESULTS}

\section{A. DESIGN SPECIFICATIONS AND SELECTED} COMPONENTS FOR THE PROTOTYPE CONSTRUCTION The design specifications of the power converter are shown in Table II.

TABLE II

SPECIFICATIONS OF THE EXPERIMENTAL PROTOTYPE

\begin{tabular}{lll}
\hline \hline \multirow{2}{*}{ Symbol } & \multicolumn{1}{c}{ Quantity } & Value \\
\hline$P_{o}$ & Output power & $1.5 \mathrm{~kW}$ \\
$V_{i}$ & Effective value of the input voltage & $220 \mathrm{~V}$ \\
$V_{o}$ & Effective value of the output voltage & $220 \mathrm{~V}$ \\
$f_{r}$ & Resonance frequency & $40 \mathrm{kHz}$ \\
$f_{s}$ & Switching frequency & $40 \mathrm{kHz}$ \\
\hline \hline
\end{tabular}

From the design specifications, the components of the power stage of the converter were selected, which are shown in Table III. In order to reduce current stress in the capacitors, parallel and series arrangement was used. 
TABLE III

EXPERIMENT PARAMETERS

\begin{tabular}{|c|c|c|}
\hline Components & Type & Value or Specification \\
\hline$S_{a}, S_{b}, S_{c}, S_{d}$ & IGBT Module & $\begin{array}{l}\text { 600V/40A/ FNB34060T } \\
\text { (On Semiconductor) }\end{array}$ \\
\hline$S_{1}, S_{2}, S_{3}, S_{4}$ & $\begin{array}{l}\text { CoolMOS } \\
\text { MOSFET }\end{array}$ & $\begin{array}{l}\text { 600V/ 30A/ IPZA60R060P7 } \\
\text { (Infineon) }\end{array}$ \\
\hline$S_{F 1}, S_{F 2}$ & SiC MOSFET & $\begin{array}{l}\text { 1200V/24A/ C3M0075120K } \\
\text { (Cree) }\end{array}$ \\
\hline$C_{f}, C_{o}$ & Film Capacitor & $\begin{array}{l}8 \times 470 \mathrm{nF} / 650 \mathrm{Vdc} \\
\text { (Kemet R76 Series) }\end{array}$ \\
\hline$C_{r}$ & Film Capacitor & $\begin{array}{l}(2 \times 100 n F+1 \times 47 n F) / 2000 V d c \\
\text { (Kemet R76 Series) }\end{array}$ \\
\hline$L_{r}$ & Resonant Inductor & $\begin{array}{l}\text { Ferrite Core N87 / } 63 \mu \mathrm{H} \\
(\mathrm{TDK})\end{array}$ \\
\hline$L_{m}$ & $\begin{array}{l}\text { Transformer } \\
\text { magnetizing } \\
\text { inductance }\end{array}$ & $305 \mu \mathrm{H}$ \\
\hline$T_{l}$ & Transformer data & $\begin{array}{l}\text { Ferrite Core N87 (TDK) } \\
\text { Litz Wire 400x38AWG }\end{array}$ \\
\hline$a$ & $\begin{array}{l}\text { Transformer turns } \\
\text { ratio }\end{array}$ & Unity \\
\hline
\end{tabular}

For the semiconductors of the input rectifier stage, which operate with the frequency of the sinusoidal input voltage equal to $60 \mathrm{~Hz}$, an IGBT module was used, as it is robust and ideal for high power and low frequency applications. For the inverter bridge of the LLC converter, CoolMOS MOSFET was chosen, due to its low series resistance and its ability to operate at high switching frequency. Finally, the $\mathrm{SiC}$ MOSFET technology presented itself as one of the most attractive choice for use in the output stage, due to its ability to withstand high voltages and low conduction losses.

\section{B. EXPERIMENTAL PROTOTYPE, CURVES AND RELEVANT WAVEFORMS}

The designed and built experimental prototype is shown in Fig. 20 and the main components used are indicated by arrows.

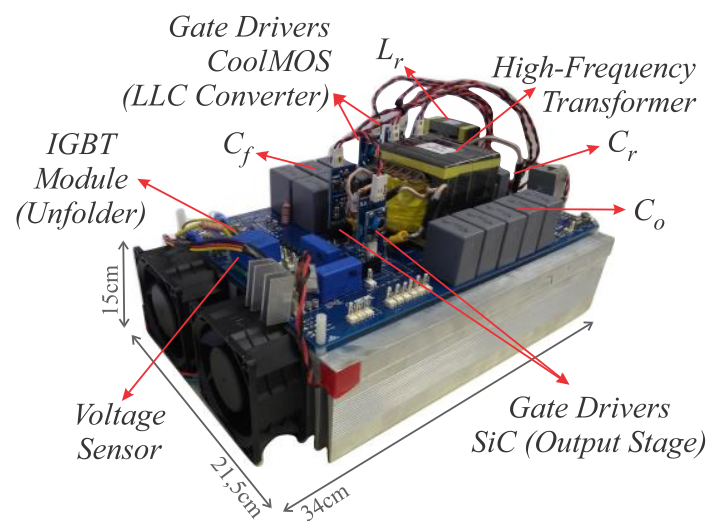

FIGURE 20. Experimental prototype designed, built and tested in the laboratory.

The experimental prototype was tested in the laboratory, with resistive load. Starting with the low frequency waveform analysis, Fig. 21 shows the sinusoidal input voltage, the rectified voltage at the output of the first stage and voltage waveforms across its power semiconductors.

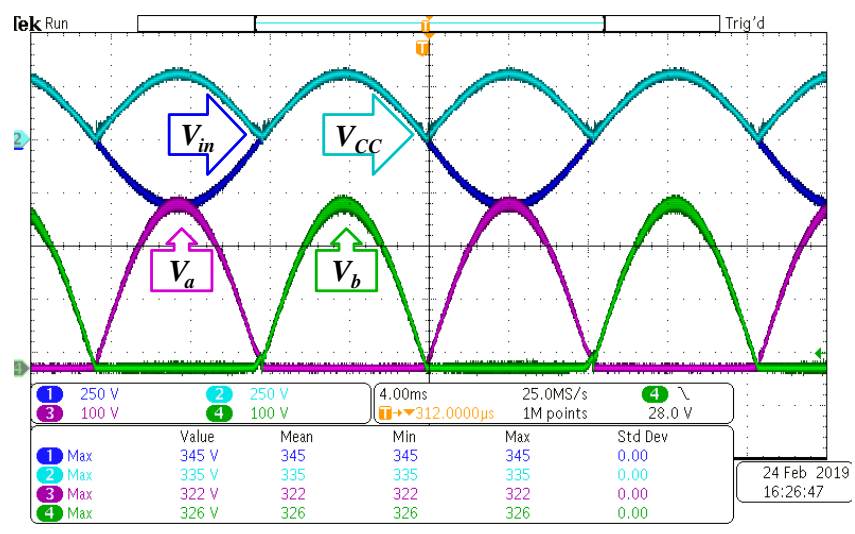

FIGURE 21. Waveforms of the sinusoidal input voltage, rectified input voltage and voltage across the IGBT's of the folding input bridge.

Fig. 22 shows the voltages across the power semiconductor of the resonant LLC converter, along with the rectified output current and the resonant inductor current.

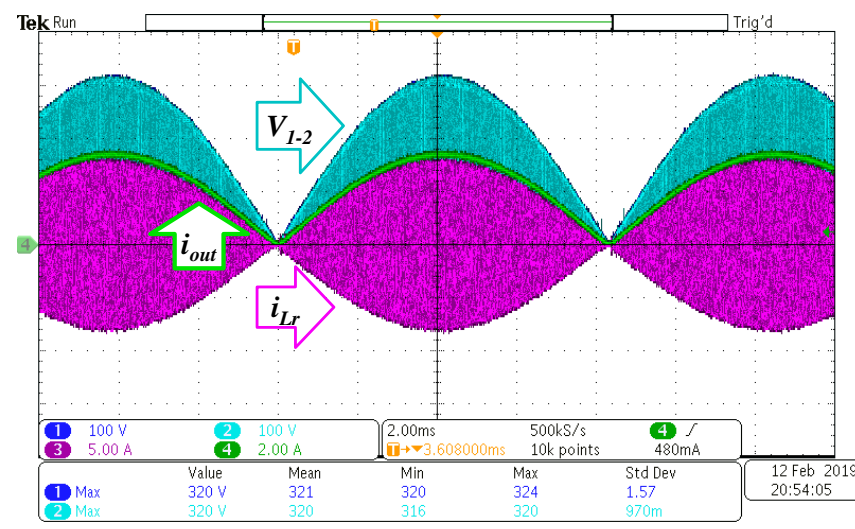

FIGURE 22. Voltage across the power semiconductors of the resonant LLC stage $\left(V_{s 1}, V_{s 2}\right)$, and resonant current and low frequency output current $\left(I_{\text {out }}\right)$.

Fig. 23 shows the currents through the output semiconductors along with the output current.

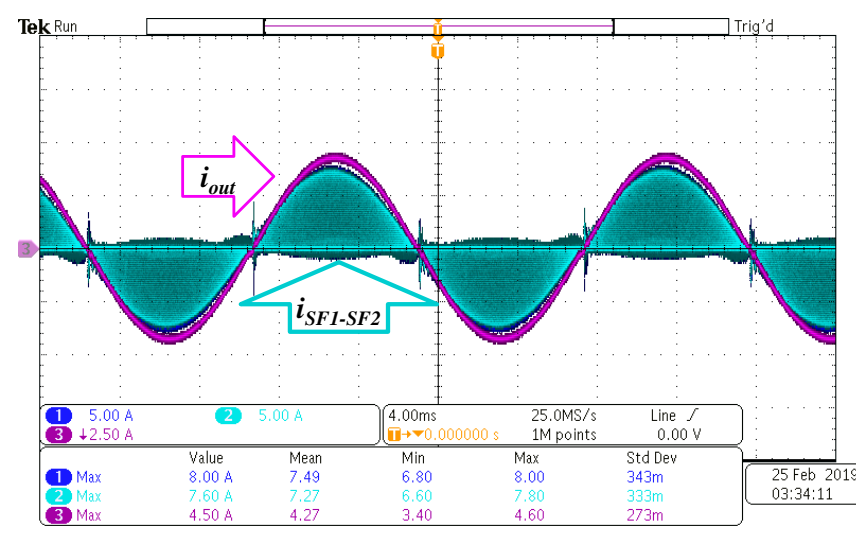

FIGURE 23. Current through the power semiconductors of the output stage, and through the load resistor. 
The voltage across the power semiconductors $S_{F 1}$ and of the output stage is shown in Fig. 24.

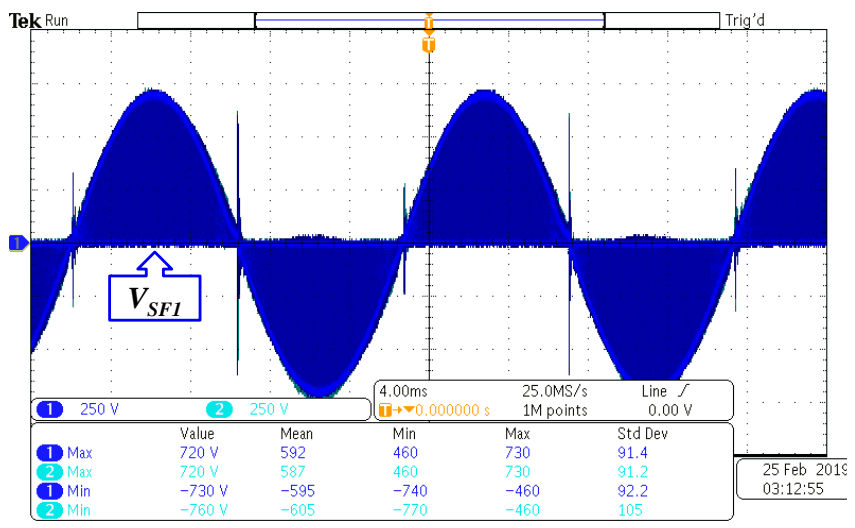

FIGURE 24. Voltage across the power semiconductors of the output stage.

The output and input sinusoidal voltage and current waveforms for operation with $1138 \mathrm{~W}$ are shown in Fig. 25 and Fig. 26, respectively.

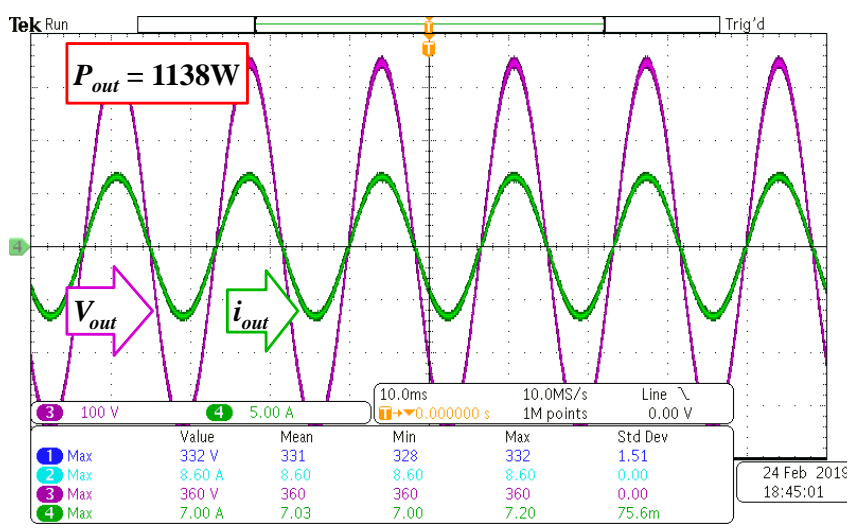

FIGURE 25. Load voltage and current waveforms for $P_{\text {out }}=1138 \mathrm{~W}$.

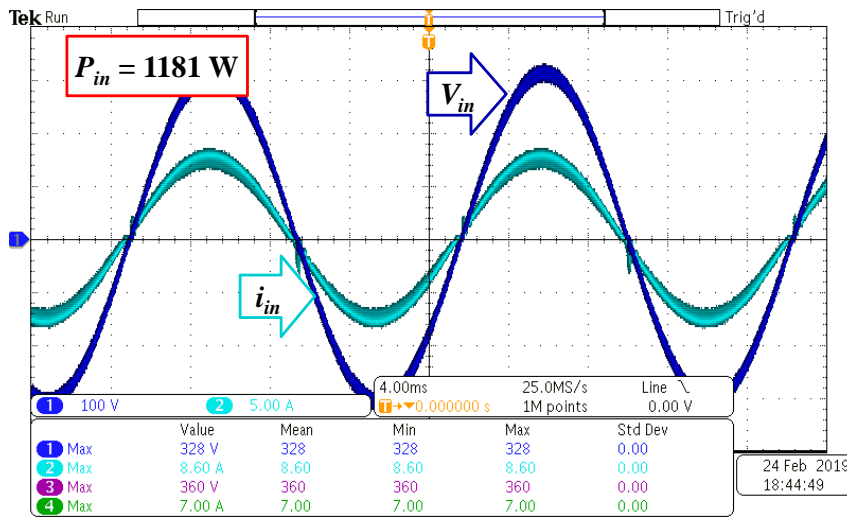

FIGURE 26. Sinusoidal input voltage and current waveforms for $\boldsymbol{P}_{\text {out }}=$ $1138 \mathrm{~W}$.

Fig. 27 shows the voltage generated by the power semiconductors of the resonant LLC converter, the current through the resonant inductor $\left(i_{L r}\right)$ and the corresponding load current that is practically constant during the high frequency switching period.

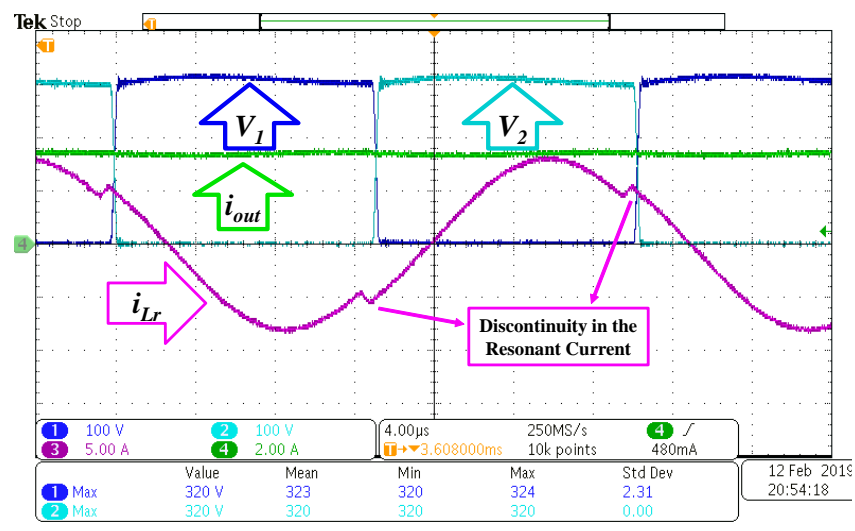

FIGURE 27. Voltage across the semiconductors of the LLC resonant stage, current in the resonant inductor and the load, at the switching frequency scale.

The voltages at the primary and secondary transformer windings terminals of the high frequency transformer, in the region close to zero crossing of the low frequency input voltage, are shown in Fig. 28, together with the winding current in the primary side.

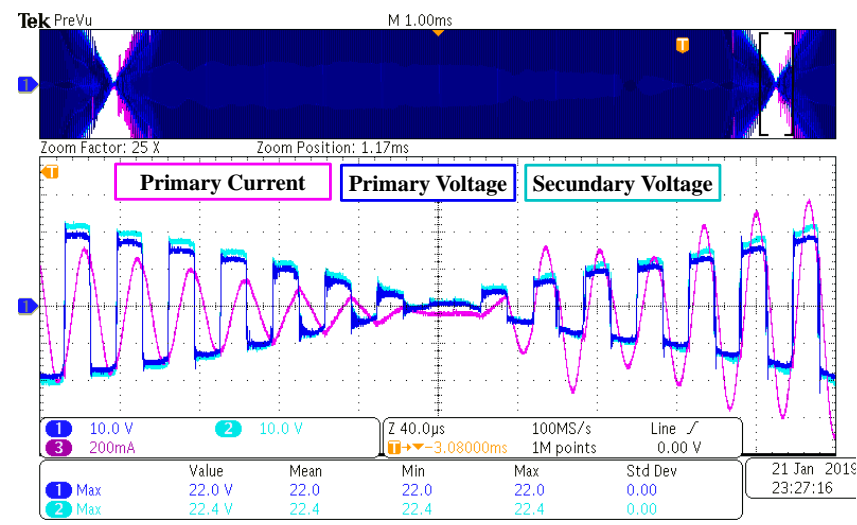

FIGURE 28. Voltages at the terminals of the primary and secondary windings of the high frequency transformer, together with the current in the windings on the primary side.

It can be noted that at the instant the current in the secondary winding of the transformer reaches zero, the current in the resonant inductor in the primary winding of the transformer is equal to the magnetizing current. This characteristic can be seen by the triangular primary current near the zero crossing of the sinusoidal input voltage.

In Fig. 29 the currents in the output stage switches are shown in detail, while detail of the voltages across the power semiconductors of the output stage switches are shown in Fig. 30. 


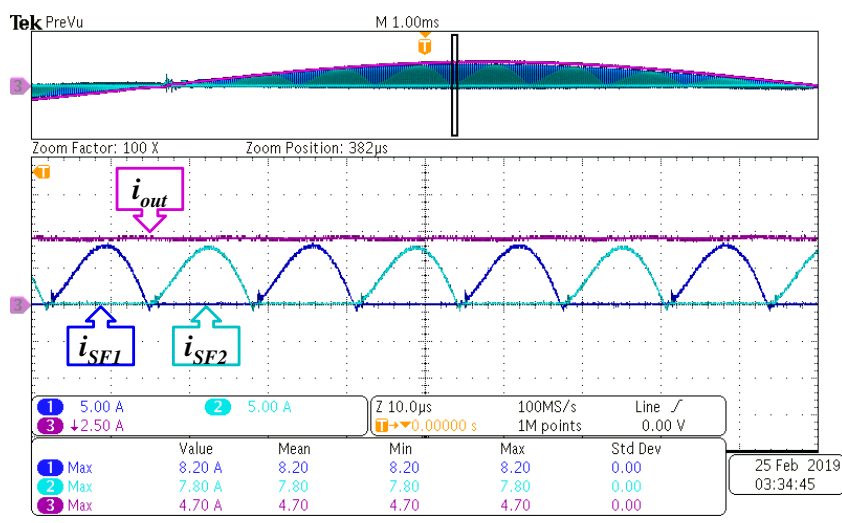

FIGURE 29. Current through the semiconductors of the output stage in detail.

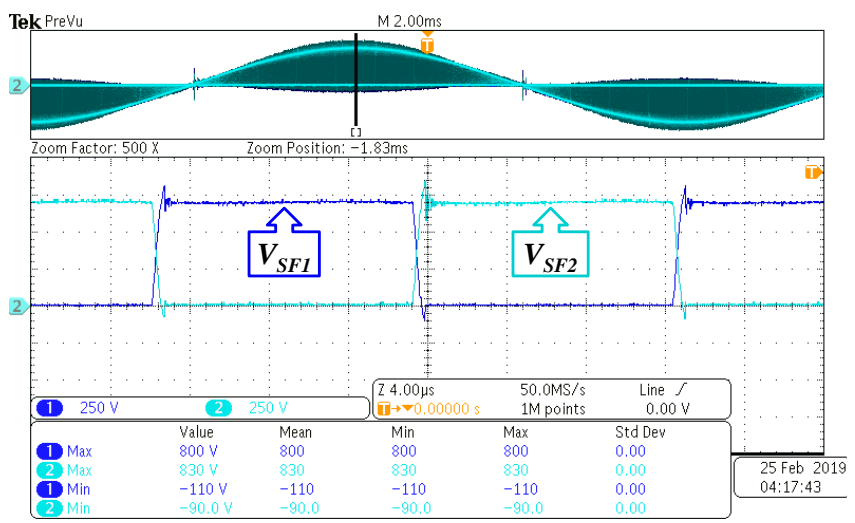

FIGURE 30. Waveforms of the voltage across the power semiconductors of the output stage.

Peak voltage can be observed across the switches at the beginning of each switching period. These spikes are caused by dead time and were expected, as stated earlier.

The relevant waveforms in the power semiconductors of the LLC resonant converter are shown in Fig. 31 and confirm the soft commutation with ZVS.

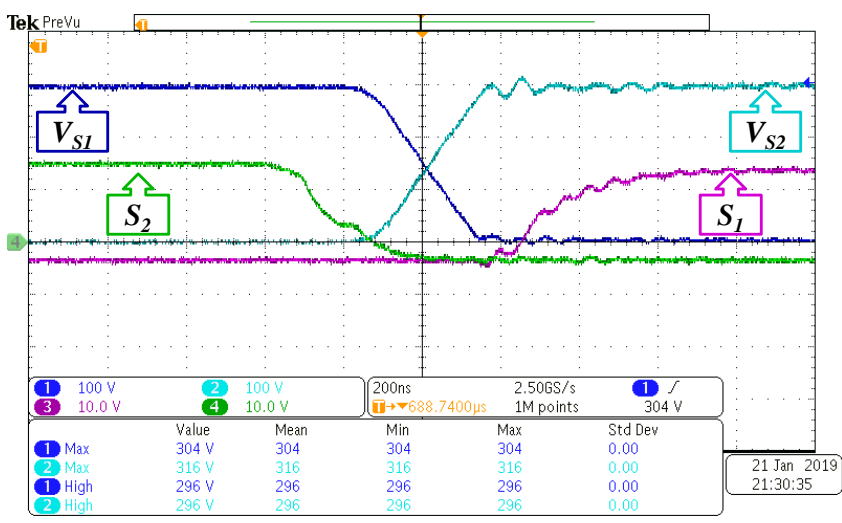

FIGURE 31. ZVS type commutation of the power semiconductors of one leg of the resonant LLC stage.

It can be seen that the switch $S_{I}$ is only gated ON after its voltage reaches zero. Thanks to the dead time and the magnetizing current, the commutation capacitor connected in parallel with $S_{I}$ is completely discharged and soft commutation takes place.

Fig. 32 shows the ZCS-type commutation of the output stage power semiconductors, for the positive half-cycle of the low frequency sinusoidal input voltage.

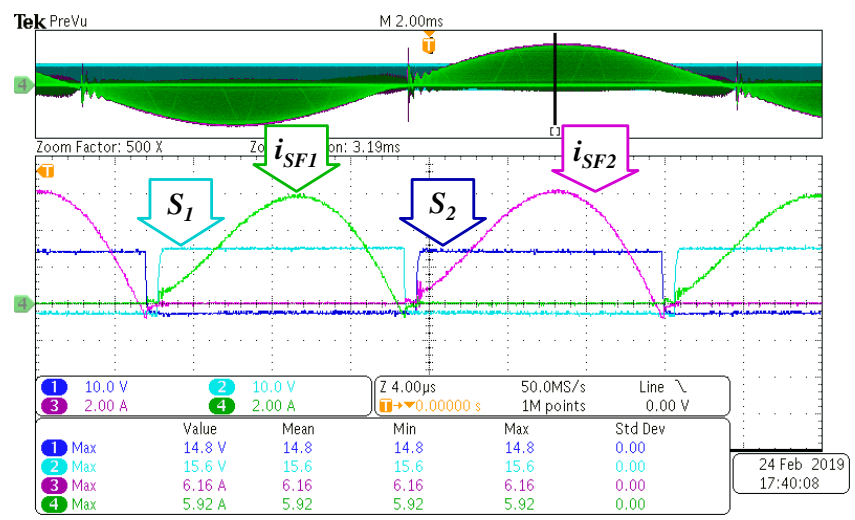

FIGURE 32. Waveforms of the voltage and current in the power semiconductors of the output stage, showing the ZCS-type commutation.

Fig. 33 shows the measured efficiency of the experimental prototype in the laboratory, against the effective input voltage, for various powers delivered to the load.

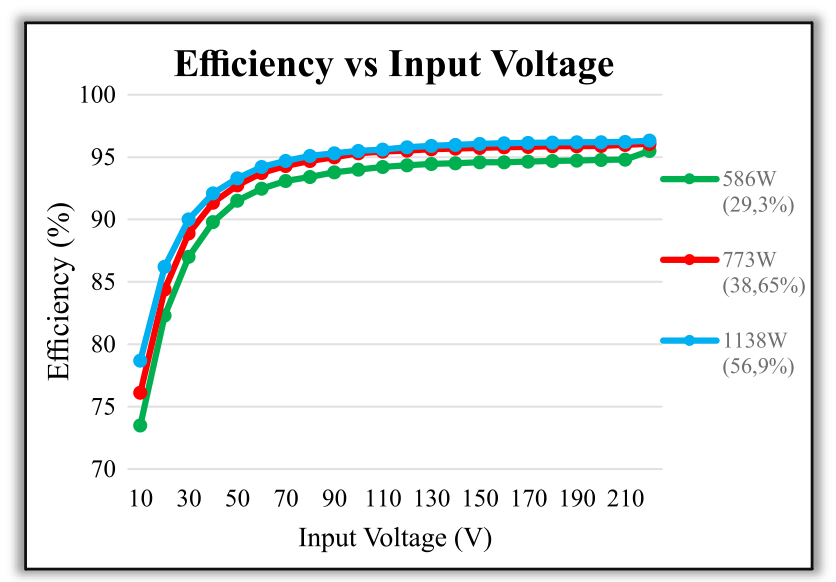

FIGURE 33. Measured efficiency against the effective value of the sinusoidal input voltage, for different processed powers.

Fig. 34 shows the experimental curves of efficiency and power factor measured at the input of the converter, for nominal voltage, as a function of the processed power. 


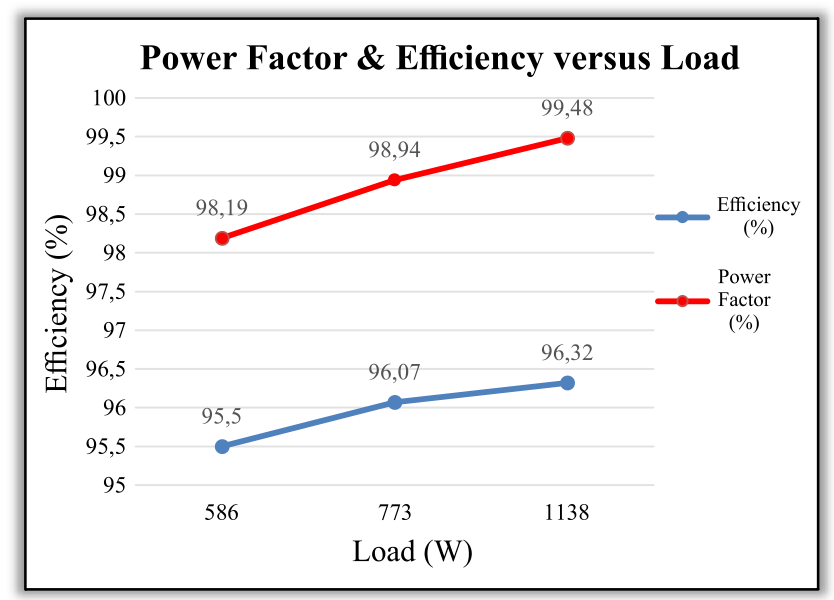

FIGURE 34. Measured input power factor and efficiency against the processed power.

\section{CONCLUSION}

An AC-AC converter with high-frequency link employing a resonant LLC converter operating in the neighborhood of the resonant frequency has been studied. The topology has a single output stage, consisting of four quadrant switches, in opposition of the conventional solution that uses two power conversion stages. An experimental prototype rated at 1.5 $\mathrm{kW}$, with the high-frequency link operating with $40 \mathrm{kHz}$ was designed, constructed and tested in the laboratory and the theoretical results have been verified. The studied architecture is suitable for application as a building block of medium-voltage power distribution solid-state transformers.

\section{REFERENCES}

[1] W. McMurray, "The Thyristor Electronic Transformer: a Power Converter Using a High-Frequency Link," in IEEE Transactions on Industry and General Applications, vol. IGA-7, no. 4, pp. 451-457, July 1971.

[2] K. Harada, F. Anan, K. Yamasaki, M. Jinno, Y. Kawata and T. Nakashima, "Intelligent transformer," PESC Record. 27th Annual IEEE Power Electronics Specialists Conference, Baveno, Italy, 1996, pp. 1337-1341 vol.2, doi: 10.1109/PESC.1996.548755.

[3] A. Q. Huang, "Medium-Voltage Solid-State Transformer: Technology for a Smarter and Resilient Grid," in IEEE Industrial Electronics Magazine, vol. 10, no. 3, pp. 29-42, Sept. 2016.

[4] J. E. Huber and J. W. Kolar, "Solid-State Transformers: On the Origins and Evolution of Key Concepts," in IEEE Industrial Electronics Magazine, vol. 10, no. 3, pp. 19-28, Sept. 2016.

[5] X. Zhao, Y. Lei, H. Wang, X. Quan and A. Q. Huang, "Design of A Medium Voltage Solid-State Transformer based on Modular AC-AC Resonant Converter and an Input-Series-Output-Parallel Architecture," 2019 IEEE Energy Conversion Congress and Exposition (ECCE), Baltimore, MD, USA, 2019, pp. 5791-5797, doi: 10.1109/ECCE.2019.8912264.

[6] X. She, A. Q. Huang and R. Burgos, "Review of Solid-State Transformer Technologies and Their Application in Power Distribution Systems," in IEEE Journal of Emerging and Selected Topics in Power Electronics, vol. 1, no. 3, pp. 186-198, Sept. 2013.

[7] J. E. Huber and J. W. Kolar, "Analysis and design of fixed voltage transfer ratio DC/DC converter cells for phase-modular solid-state transformers," 2015 IEEE Energy Conversion Congress and Exposition (ECCE), Montreal, QC, 2015, pp. 5021-5029, doi: 10.1109/ECCE.2015.7310368.
[8] L. F. Pacheco and I. Barbi, "A Bidirectional AC/AC Series Resonant Converter with High Frequency Link," 2018 13th IEEE International Conference on Industry Applications (INDUSCON), São Paulo, Brazil, 2018, pp. 305-311, doi: 10.1109/INDUSCON.2018.8627182.

[9] F. Pöttker, I. Barbi, "LLC Resonant Converter," in Soft Commutation Isolated DC-DC Converters, $1^{\text {st }}$ ed., Switzerland: Springer, 2018, pp. 141-186.

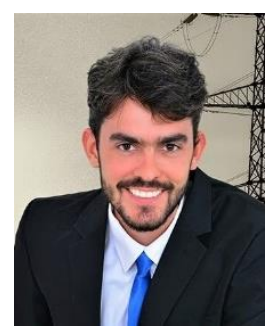

LEONARDO F. PACHECO NASCIMENTO (Student Member, IEEE) was born in Salvador, BA, Brazil in 1992. He received the B.S degree in electrical engineering from the Federal Institute of Bahia, Vitória da Conquista, in 2017 and the M.S. degree in electrical engineering from the Federal University of Santa Catarina, Florianópolis, in 2019.

From 2018 to 2019 he was an internship researcher with the Brazilian Power Electronics and Renewable Energy Institute (IBEPE). Since 2020, he has been a doctor's degree student with the Fotovoltaica/UFSC Solar Energy Research Laboratory at Universidade Federal de Santa Catarina, under the orientation of prof. Ivo Barbi. His research interests include power electronics, solidstate transformers, inductive power transfer and soft commutation.

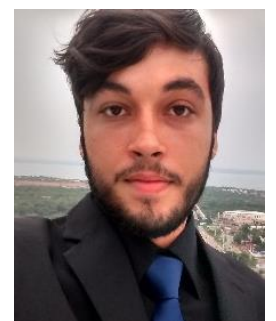

KAIO C. M. NASCIMENTO (Student Member, IEEE) was born in Sítio Novo, MA, Brazil in 1977. He received the B.S. degree in electrical engineering from the University of Tocantins, Palmas, in 2017 and the M.S. degree in electrical engineering from the Federal University of Santa Catarina, Florianópolis, in 2020

From 2018 to 2019 he was an internship researcher with the Brazilian Power Electronics and Renewable Energy Institute (IBEPE). Since 2020, he has been a doctor's degree student with the Fotovoltaica/UFSC Solar Energy Research Laboratory at Universidade Federal de Santa Catarina, under the orientation of prof. Ivo Barbi. His research interests include power electronics, solid-state transformers, isolated bidirectional DC-DC power converters, resonant converters and soft commutation.

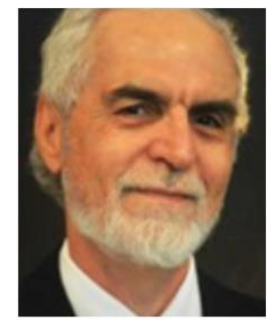

IVO BARBI (Life Fellow, IEEE) was born in Gaspar, Brazil. He received the B.S. and M.S degrees in electrical engineering from the Federal University of Santa Catarina (UFSC), Florianópolis, Brazil, in 1973 and 1976, respectively, and the Dr.Ing. degree in electrical engineering from the Institut National Polytechnique de Toulouse (INPT), Toulouse, France, in 1979.

He founded the Brazilian Power Electronics Society (SOBRAEP), the Brazilian Power Electronics Conference (COBEP), in 1990, and the Brazilian Power Electronics and Renewable Energy Institute (IBEPE), in 2016. He is currently a Researcher with the Solar Energy Research Center and a Professor Emeritus in electrical engineering with UFSC.

Prof. Barbi served as an Associate Editor for the IEEE Transactions on Industrial Electronics and IEEE Transactions on Power Electronics for several years and received the 2020 IEEE William E. Newell Power Electronics Award. 